\title{
Examining professionals' critical thinking about children who pose a serious threat to others
}

\begin{abstract}
Concerns have been raised about the quality of childcare professionals' critical thinking and analytical skills. This study examines the critical thinking demonstrated by professionals when discussing risk in relation to vulnerable children. Data was collected from 30 consultation meetings, each of which focused on assessing the risks of a child who presented a serious threat of harm to others. Discourse analysis is used to examine the way in which critical thinking about risk is discussed at the consultation meetings. The findings suggest that critical thinking is demonstrated by professionals in ways that differentiate between potential harm and actual harm, and in relation to harm children pose to themselves and to other people. Also, the willingness of professionals to ask relevant questions and challenge each other is an important way of prompting individuals to demonstrate critical thinking. However, professionals tend to demonstrate a relatively narrow conceptualisation of critical thinking. This narrow conceptualisation cannot be reduced solely to the abilities or traits of an individual or professional group and it is argued that the bureaucratic and procedural demands of organisations in relation to vulnerable children may be an important factor in limiting the way professionals demonstrate critical thinking.
\end{abstract}

Key words: critical thinking risk vulnerable children

\section{Introduction}

Numerous reports, research and practice reviews within child welfare have expressed ongoing concern over the quality of practitioners' critical thinking and analytical skills (Munro, 2011; Turney and Ruch, 2016). Inadequate attention has been given to the way knowledge is produced in practice contexts and what practitioners actually do in conceptualising cases (Gray and Schubert, 2013). This study contributes to this underresearched area by examining the critical thinking used by professionals when assessing children who present a serious risk of harm to others. Children who harm others present practitioners with complexities and dilemmas in terms balancing a child's vulnerability (e.g. trauma, attachment issues) alongside a need to impose controls and sanctions in order to manage the risk generated by the child (Barter, 2013). Focussing on the way critical thinking and risk present when professionals assess children who harm others provides insight into professionals' thinking, which has relevance to: outcomes and decision making; errors and judgements; education of childcare practitioners, and; the broader organisational context. Despite the importance attributed to critical thinking, Gambrill (2012) believes the growth in procedural guidance in social work in the UK and internationally is not conducive to such thinking. This matters to childcare professionals and academics in social work and health related disciplines who want to know what critical thinking about risk looks like in practice and how it can be adversely affected by the bureaucratic and procedural demands of organisations.

\section{Rationale for linking critical thinking and risk}

Critical thinking 'is considered to be at the heart of practice' (Sheppard et al, 2018, p.15) 
and is a cognitive process that cannot be separated from a range of individual (e.g. emotions, experience, education) and situational factors (e.g. organisational expectations, culture and procedures) (Taylor and White, 2001). For Brown and Rutter (2008) critical thinking enables social workers to make the best quality decisions for the complex situations they encounter. Yet, the concept of critical thinking remains elusive and there are no agreed definitions across professions or in social work (Deal and Pitman, 2009). Kuhn (1991, p. 4) provides a useful definition whereby critical thinking embodies reasoned argument and is 'a process of weighing pros and cons or positive and negative evidence regarding alternatives has at some level of consciousness gone into an argument'. In a social work context Sheppard et al. (2018) believe critical thinking requires practitioners to engage more in conscious and deliberative thinking rather than intuitive or heuristic thinking which is automatic, spontaneous and fast. This distinction is important because various studies (e.g. Helm, 2011) show social workers are more ready to adopt heuristic or intuitive methods in preference for processes requiring deliberative and analytical thinking. According to Gambrill (2012) this is problematic because intuitive and heuristic thinking are more prone to errors, especially in terms of the tendency to focus on the familiar or obvious whilst ignoring the complex and less predictable aspects of practice. The role of critical thinking as a form of deliberative and reasoned thinking is therefore, particularly important when understanding risk in complex situations and where errors have to be minimised.

Practitioners have to understand the 'multidimensional nature of the risks' in the assessment and management of children who harm others (Baker, 2008, p. 1475). Given that children who harm others have often experienced trauma and abuse (e.g. Allardyce and Yates, 2013) any attempt to address risk requires professionals to move beyond a narrow focus on the 'index offence' and adopt a broad view of the child's development (Hackett et al., 2013, p. 243). Whilst it is therefore, essential to assess the negative or adverse nature of a child's risk of harm to others (e.g. violence) any assessment must also incorporate a strengths-based approach where appropriate steps are taken to promote a child's resilience and protective factors (e.g. building confidence, friendships) (Daniel et al., 2010). Attaining this balance within the assessment process is often difficult to achieve. Risk is a complex and ambiguous concept and is constructed in radically different ways in child welfare systems nationally and internationally (e.g. Mayer et al, 2009). Definitions tend to recognise the positive and negative dimensions to risk, although its concern for social work has primarily been linked to harm, likelihood, reduction and prevention (Hardy, 2017). The organisational response to risk has a particular impact on practitioner thinking. Long-standing concerns persist about the way childcare professionals have their thinking constrained by the increasingly procedural and bureaucratic demands of child welfare organisations (Crawford, 2004; Lamming, 2009; Munro, 2011). In particular, Whitaker and Harvard (2016) argue that organisations are increasingly risk averse, where a culture of blame exacerbates practitioners' fear and limits their ability to think. Whilst critical thinking might be widely recognised as being good for practice, Turney and Ruch (2016, p 681) note that 'it is difficult both to do well and to embed effectively in organisational structures'. This raises fundamental issues about the way in which professionals conceptualise risk in complex practice situations.

\section{Methods}


This study examines the critical thinking demonstrated by professionals when discussing risk in relation to vulnerable children. The study uses data from a project based in Scotland that offers a specialist psychological and social work service for the assessment and management of children who present a serious risk of harm to other people and who are themselves at risk. Whilst the project offers a range of services, this study focuses on the consultation meetings which provide an assessment of the child's needs and risk with the aim of supporting the professionals who are working with the child. The project is not located within mainstream social work, however, the consultation meetings are relevant to the profession in four key ways: many of the children discussed in the meetings have previous and/or ongoing social work intervention due to experiences of abuse and neglect; most of the children are under the care of the local authority and cared for out with their family home; the harm children present is often towards other children which requires child care and protection; and, the thinking demonstrated by those professionals in the meetings is likely to be influenced, at least to some extent, by experiences and knowledge of social work. By examining the consultation meetings the study aims to:

- identify the extent to which critical thinking about risk is demonstrated by professionals when discussing children who are harmful to others;

- examine any patterns of critical thinking and extent to which certain aspects are more relevant when discussing risk.

Data is analysed from 30 consultation meetings (hereafter, referred to as meetings). Referrals to the project are accepted for children who are aged between 12-18 years. Almost all of the children's ethnicity was white and one child had Asian ethnicity. Approximately 200 meetings have taken place within the project over a four-year period with more frequent referrals for boys (86\%) than girls (14\%). Purposive sampling is used to gain a gender balance and 15 female and 15 male cases are randomly selected for this study. Whilst the proportion of girls selected for the study is disproportionate to the higher referral rate of boys, it allows for issues of gender to be considered in the analysis of critical thinking. The study adheres to internationally accepted ethical guidelines and is approved by the University Ethics Committee. All of the professionals attending the meeting gave consent for the content to be used for research purposes. All names have been changed to protect those individuals discussed at the meetings and those professionals taking part.

Following the criteria cited for qualitative studies (e.g. Fusch and Ness, 2015) the analysis of 30 meetings is considered sufficient to allow for data saturation to occur, patterns of data to be established and for the researchers to be confident that the use of coding in the study is relevant and applicable. The meetings are audio recorded and comprise of between five and 10 professionals. There are normally three professionals from the project, comprising of at least one social worker and one psychologist, and usually two or more professionals who are seeking the consultation (i.e. social worker, residential worker, teacher, psychologist, police officer, psychiatrist and nurse). Social workers and psychologists are the most commonly represented professionals at each meeting. There are no children, family or laypersons attending the meetings. Although service user participation and involvement in social work and other caring professions has been a significant theme for over two decades (D'Cruz and Gillingham, 2017), the rationale for excluding service users in the meetings is to create a 
forum where professionals are more able to be honest about their feelings, candid about mistakes and willing to disagree with colleagues. The meetings are scheduled for a duration of two hours.

Discourse analysis is used to analyse the data. Discourse analysis is a method to examine written or verbal language and its relationship to the context in which it is used (Hardy et al., 2004). Whilst there are a variety of approaches and definitions of discourse analysis, Potter's (1996) approach is useful because of its focus on social phenomena that is interpretive and constructionist; hence, it is deemed applicable to this study given that critical thinking and risk are socially constructed concepts which are open to interpretation by the professionals and researchers. Discourse analysis is preferable to a content analysis because it allows for coding that includes counting the occurrence of certain phenomena and identifying patterns in the way language is used in a running discourse involving different speakers in a given context (Crawford, 2004). Coding enables the researchers to identify any patterns in the way professionals use critical thinking about risk in the meetings. In this study, Maclellan and Soden's (2001) framework of critical thinking is used because it offers a concise set of categories that can be coded. The framework was devised to identify critical thinking in student assignments, however, the generic nature of the categories make them useful for examining risk. The assumption in this study is that if these categories are useful for examining students' thinking and written work, professionals will be able to demonstrate them in verbal discussions about important matters such as risk. As previously noted, the complexities in defining critical thinking make any form of coding problematic for an empirical study. Using a framework of critical thinking allows for a broader exploration of the topic and whilst one or more categories does not necessarily demonstrate critical thinking per se, each category contributes to our understanding of the way professionals think about risk. Whilst other frameworks and approaches (see for example Barnett, 1997) might provide a more extensive understanding of critical thinking they are not readily applicable or adaptable for a practical study. There are six categories to Maclellan and Soden's (2001) framework of critical thinking:

1. unpacking concepts - ability to unpack or break down ideas, concepts or theories;

2. recognising contradictions - differentiating between viewpoints and counterarguments;

3. development - explaining a phenomenon, joining ideas together to form lines of arguments;

4. providing evidence-supporting or justifying assertions;

5. examining implications of evidence-generating hypotheses about consequences and examining the relationships between key factors;

6. alternative interpretation-questioning or challenging an interpretation of the evidence and offering an alternative.

The coding uses specific terminology in order to identify occurrences of the categories of critical thinking about risk. The term 'children' is used to refer to the 30 children who are the focus of the meetings. The term 'other people' refers collectively to any other individuals (adult or child). For the purpose of this study risk is considered as any action or behaviour 
that causes potential harm or actual harm to the children or other people. Potential harm relates to actions or behaviour that might cause serious injury, whereas actual harm relates to serious injury occurring. This use of risk aligns with the reasons for the child's referral to the project and includes occasions where a child causes harm to themselves (e.g. self-harming, drug misuse), to other people (e.g. violence, exploitation) and also where the child experiences harm from other people (e.g. parental neglect, sexual grooming by an adult). The six categories of critical thinking are used with the four domains of the 'child', 'other people', 'potential harm' and 'actual harm'. This provides 24 permutations for coding critical thinking about risk. A matrix is used to code data for the 30 meetings. The researchers listen to the recordings for each meeting and use the following process to code data: (1) when risk is discussed in a way that demonstrates critical thinking it is coded in relation to the six categories; (2) the coding differentiates between potential harm and actual harm; and, (3) there is further differentiation in the coding between risk for the children and other people. The coding from the 30 matrices is compiled and analysed in terms of the way critical thinking is demonstrated in relation to risk.

A limitation of this study design is that the categories of 'critical thinking' and 'risk' are predetermined by the researchers, which may not fully encapsulate the intended meanings of the professionals attending the meetings. Within the meetings there is no attempt to differentiate between professional groups, hence it is not clear how factors such as power, status, identity or confidence might impact on the critical thinking demonstrated at the meetings. Examining the negative or danger aspect of risk provides greater focus for the study and reflects the reasons why children are referred to the project, however it does detract from a multidimensional approach where certain risks are viewed as a positive aspect of child development. Coding the thinking of other professionals entails a degree of subjectivity and judgment. In an attempt to minimise bias, the researchers code each meeting and on those occasions where there are differences between them, the recording is listened to again until the researchers reach agreement. On those occasions where the same risk is discussed at different periods in the meeting, it is coded only once. Given that all of the meetings were completed prior to the research being conducted there is no obvious bias which might influence the nature of the professionals' critical thinking.

\section{Findings}

The findings show patterns in the way professionals demonstrate critical thinking based on the coding used in this study. These patterns suggest that critical thinking is linked, at least to some extent, to the priorities that professionals have when discussing children who pose a serious threat to others. This is reassuring in that professionals are able to differentiate between important factors when considering risk. However, given the critical thinking is restricted to three of the six categories used in this study, it suggests that certain categories are more relevant and easier to apply or a relatively narrow conceptualisation of critical thinking is used by professionals. In order to explore this aspect in more depth it is necessary to examine the frequencies and patterns of critical thinking. 
There were a total of 1050 instances of critical thinking about risk from the 30 meetings. The exploratory nature of the study means it is not possible to know if the frequency of critical thinking is typical of other forums or whether the categories of critical thinking are of similar quality and relevance to the decision making and outcomes of the meetings. The instances of critical thinking for the four domains of potential harm and actual harm in relation to the children or other people are presented for boys (n:15) and girls (n:15) in table 1.

Table 1- insert

Overall, professionals are more likely to demonstrate critical thinking about actual harm (n: 612) than potential harm (n: 438). Critical thinking about actual harm is also higher when it relates to other people (n: 404) rather than the children (n: 208). This is perhaps not surprising given the children are referred to the project because of the serious threat they present to other people. The frequency of critical thinking in terms of potential harm (n: 219) and actual harm (n: 208) to the children suggests that whilst these children present a threat to other people, they are also at risk themselves. In terms of gender, instances of critical thinking are more frequent for girls (n: 554) than boys (n: 496). The frequency of critical thinking for potential harm is almost double for girls (n: 142) than boys (n: 77) when the potential harm relates to the children. A similar pattern is shown for actual harm to the children with instances of critical thinking for girls (n: 148) over double that of boys (n: 60). These gender differences may reflect the higher risks that girls experience from their own actions (e.g. self-harm, drug misuse) or from the actions of other people (e.g. sexual exploitation) compared to boys. Alternatively, when the risk relates to other people the frequency of critical thinking is higher in relation to boys (n: 217) than girls (n: 187) when discussing actual harm. Similarly, the frequency of critical thinking about the potential harm for boys (n: 142) is almost twice that of girls (n: 77) when it relates to other people. In general, the use of critical thinking appears to vary according to the child's gender, level of harm and vulnerability and the seriousness of the threat towards other people. This indicates that some risks warrant more critical thinking than others. Critical thinking is therefore, not used in a blanket way, but rather in ways that often differentiate between factors relating to the individual and levels of risk.

There is also a clear differentiation in the demonstration of the categories of critical thinking. An analysis of the six categories shows a pattern in the way critical thinking is used by professionals when discussing risk. Figure 1 shows the frequency of the six categories of critical thinking in relation to risk (potential harm and actual harm) for the children and other people.

Figure 1- Insert

Irrespective of gender or the four domains (i.e. potential harm, actual harm, the children or other people) three of the six categories are used much more frequently; development, providing evidence and implications of evidence. Extracts are selected from the discussions 
in order to provide an insight into the way critical thinking about risk appears in a practice context.

The 1050 instances of critical thinking about risk are presented in order of frequency (high to low). The highest frequency of critical thinking is demonstrated in relation to the category of 'development' (n: 533) with risk to others (n: 301) being more frequent than the risk to the children (n: 232). The category of development tends to have a combination of description and analysis. Generally, it is the use of questions by other professionals in the meetings that allows for more explanations, which then increases the frequency of the category of development and often leads to other categories of critical thinking being demonstrated. In the following extract, critical thinking for the category of development is mostly descriptive until the teacher responds to the question from the psychologist.

Teacher: Claire planned this trip, taking Rachel [step sister] for a walk. Rachel had just shorts and a vest. Claire was similarly dressed but had a rucksack full of provisions, waterproofs. Claire exhausted Rachel by going up a hill and down and up and confusing Rachel and getting her lost. Rachel was besides herself and so angry with herself with being taken in by Claire, but also because she was so fearful.

Social Worker: were the police called?

Teacher: Yes. Claire ran off and Rachel was left with an exhausted dog as well... Rachel managed to get down by following a stream. [Dad] was looking for them at that time.

Psychologist: did she [Claire] ever say what she was intending? Why get rid of Rachel?

Teacher: Because she didn't want Rachel with her. Because she wanted to do harm to Rachel and their relationship. They were getting on so well, so it gets sabotaged.

Psychologist: she put her at quite a serious risk.

The question by the social worker seeks important information however; it is a closed question and as such may be less likely to invoke further critical thinking. The first question by the psychologist is also closed but is followed by an open question. Asking a 'why' question invites the teacher to give an explanation of Claire's behaviour towards her stepsister. The use of questions to elicit additional information or seek clarification is common to all of the meetings, albeit to varying degrees. Professionals should therefore, be encouraged to ask each other probing questions as a strategy for encouraging critical thinking. Conversely, overly descriptive accounts of risk should be discouraged, especially when presented as a 'list' of problematic behaviours, which usually occurs when a background or history of the child is being presented. These descriptive accounts of risk are time consuming and reduce opportunities for critical thinking.

The category of 'providing evidence' has the next highest frequency of critical thinking (n: 314) with risk to others (n: 182) being higher than risk to the children (n: 132). This category 
is usually linked to a discussion which follows on from the category of development, although sometimes it occurs at a later period in the meeting. The following extract by a residential worker is in response to the social worker expressing concerns about Ashley (14 years), who is self-harming.

Residential worker: she tied a ligature around her neck and shouted for one of our casual [temporary] members of staff to come. She told the staff to move away from behind the door and said, 'I have a tie tied around my neck'.

The category of providing evidence is an important aspect of critical thinking in that it offers concrete and verifiable information. Yet, the category of providing evidence is only apparent in 59\% of occasions where category of development is demonstrated. This suggests that professionals often discuss risk without any concrete or verifiable evidence. Of course, it is not always possible for a professional to provide evidence about specific behaviour or risks because of the gaps in information that exist about a child's background and/or current life. Nevertheless, discussing the nature of evidence (or its absence) might help professionals to differentiate between more deliberative thinking and intuitive or heuristic thinking. In doing so, it might help reduce errors in judgment because the evidence is considered in a more conscious manner.

The category of 'implications of evidence' (n: 116) is almost twice as likely to be demonstrated in relation to other people (n: 78) than the children (n: 38) and occurs in approximately one third of those instances where the category of evidence is demonstrated. In the following extract, the implications of evidence gives the social worker's interpretation of why Linda's latest violent act is the most severe to date:

Social worker: She was developing a pattern of putting people down on the ground, usually from behind and pulling their hair. She initiated the assault and kicked him. Then other members of the group got involved. All of the young people have been charged with attempted murder.

The implications of the evidence, according to the social worker, is that a pattern of behaviour has been developing 'with five serious assaults in six months' and when Linda's individual assaults become linked with the offending behaviour of her peers there is an escalation in the severity of her violence. The category of implications of evidence is therefore important in gaining a professional's interpretation of the risk. The ability to interpret evidence is crucial to good decision making and shows willingness of a professional to present a viewpoint. However, given this category is demonstrated in only one third of those instances where the category of providing evidence is present, it appears that whilst professionals can often provide concrete evidence they are much less likely to offer an interpretation. This shows a limitation in the way professionals think about risk. Essentially, it is difficult to understand how assessments can be effective when professionals are often unable or unwilling to interpret evidence about risk.

There are much lower frequencies for the remaining three categories of critical thinking: unpacking concepts (n: 46), alternative explanations (n: 24) and recognising contradictions 
(n: 17). Despite the lower frequencies, these categories of critical thinking provide important information about risk, hence it is useful to consider an example of each category. The category of 'unpacking concepts' is twice as likely to be demonstrated for other people (n: $31)$ than the children (n: 15). The following extract illustrates this category of critical thinking in relation to Frank's (17 years) 'hypersexual' behaviour.

Psychologist: He is hypersexual. He is sexually preoccupied and he's looking at pornography to an obsessive degree. He is also disinhibited ... and it sounds like he provides incriminating evidence. I think he poses a risk to the general public as well... Whatever the dynamic is with the older adult ... for someone to use sexual intimidation to keep you out of your own bed is really unusual. He doesn't sound like he has the capacity to act out of kindness

Unpacking the term hypersexual gives additional knowledge of the risk Frank presents to other people. Applying the term to Frank's life also helps to show the complexity of the behaviour and the underlying reasons. The category of unpacking concepts might therefore, be particularly useful in ensuring a more in-depth understanding exists between professionals when using specific terminology, complex concepts or new ideas. This will help to ensure a shared understanding exists, which is crucial when different professionals work collaboratively with vulnerable children displaying concerning behaviours.

The category of 'alternative explanations' is more than three times as likely to be demonstrated with other people (n: 19) than the children (n: 5). An extract in relation to Donald (14 years) demonstrates the category of alternative explanations in response to the use of the term 'toddler' by the residential worker when discussing Donald's behaviour and the way he is 'cuddled' by residential staff after a 'tantrum'.

Psychologist: He is not a toddler. There is a real dynamic here. His profile is really concerning. You have to test the hypothesis that this is a manipulation. He has a sexualised need with your relationship and ... there is a risk associated with that. Here is a boy who is a chameleon. Here is a boy whose system is willing to interpret his behaviour as a toddler tantrum even although he has hospitalised someone, he has broken someone's leg and is sexually aroused whilst strangling someone... You have to let go of the toddler and attachment, and really start to set boundaries around his behaviour. Maybe this is just me, but 14 year old boys do not generally want to be touched or tucked in [to bed].

This alternative explanation provides a different perspective of the risk from a boy who is in residential care and has accrued a number of sexual offences and physical assaults, including violence to residential staff. As such, it challenges the residential staffs' motivations and justifications for their approach to dealing with Donald. Challenging the perspectives of other professionals either directly or by offering an alternative explanation is crucial in broadening an understanding of risk, especially when there is lack of insight or where more heuristic and intuitive thinking has prevailed. It might also help individuals to reflect on their practice in light of the alternative explanation. In this sense, the category of alternative explanations re- 
affirms critical thinking as a process, which can assist in developing new ideas and perspectives as well as helping professionals to reflect on practice.

The category of 'recognising contradictions' is more than twice as likely to be demonstrated in relation to other people (n: 12) than with the children (n: 5). An extract in relation to Peter (17 years) conveys the risk he presents to women, and the court's decision to release him rather than place him on remand [keeping him in custody until the court case].

Psychologist: why is he not on remand?

Social Worker: Exactly. We could not believe it. He was up that day [in court] for three rape charges. He just walked out of the court.

Throughcare Worker: There was actually a recommendation from the police who wrote a statement to the Fiscal's office [state prosecutor]. They had gone up with it and literally handed it in to the Procurator Fiscal to say this guy should not be allowed out.

At a later point in the meeting the conversation refers back to Peter's liberty.

Psychologist: If you can't get him on remand then secure care is your option.

Don't see him alone and have police presence.

Throughcare worker: we never see him alone

Psychologist: he is really unstable ... the risk is very serious for violence... At the moment the risk he presents to the public is huge.

The category of recognising contradictions helps to convey inherent tensions and complexities that are often integral to risk. The extract conveys disbelief amongst the professionals in the meeting that the court system allowed a very dangerous individual to remain in the community. There is no obvious attempt to convey or seek further information about the court's rationale, which suggests that some professionals do not believe it is necessary to consider a different perspective in any depth when they hold their own perspective to be correct. Despite being the least frequently used category, it shows the contradictory way in which some professionals understand and act in relation to risk, even with children who poses extreme danger to the public.

Overall, the findings suggest that critical thinking is used in ways that often differentiate between factors relating to the individual and levels of risk. The willingness of professionals to ask relevant questions and challenge each other is an important way of prompting individuals to demonstrate one or more categories of critical thinking. Whilst this interaction is a key element to enhancing critical thinking, it is generally restricted to three of the six categories used in this study. This suggests some categories are more relevant, easier to apply or a relatively narrow conceptualisation of critical thinking about risk prevails in a practice context. 


\section{Discussion}

In this study professionals demonstrate critical thinking in ways that differentiate between levels of harm, vulnerability and gender. Whilst it is impossible to know if the thinking demonstrated by professionals in the meetings is similar to mainstream social work agencies, the focus of the assessment on child development, safety and protection suggests that much of the thinking is highly relevant across different childcare settings. There remains a problem, however, in explaining why certain categories of critical thinking about risk are used more frequently than others. A possible explanation is that some professionals have limited critical thinking abilities and/or some categories of critical thinking are more difficult to demonstrate. Sheppard et al's. (2018, p.15) study of social work students shows a 'huge diversity of CT [critical thinking] capabilities' and concluded that 'it is a serious concern in a profession where CT is considered to be at the heart of practice'. Similarly, Benbenishty et al's. (2003) study suggests that social workers are able to demonstrate basic level arguments and offer inferences, however, few are able to offer rebuttals and qualifiers unless specifically prompted. The current study reflects some of these concerns given that three of the categories of critical thinking are demonstrated so infrequently when professionals discuss risk. However, since the patterns of critical thinking in the current study exist across a range of meetings involving different professionals, it cannot be reduced solely to the abilities or traits of an individual or professional group, hence wider attitudinal and system factors have to be considered.

There are longstanding criticisms of overly bureaucratic procedures and guidance that limit the ability of professionals to think effectively and creatively (e.g. Crawford, 2004; Lamming, 2009; Turney and Ruch, 2016). The bureaucratic and procedural culture within organisations might not affect all forms of critical thinking in the same way and offers some explanation as to why certain categories of critical thinking in this study are used more frequently by professionals. The categories of development and providing evidence are the most frequently cited and this reflects the importance of professionals being able to explain and provide evidence of risk. These categories align with the needs of an organisation that prioritises standardisation and control. Alternatively, overly bureaucratic procedural practices do not require childcare professionals to interpret evidence beyond the guidance of the organisation. The prescriptive guidance is designed to shape practice in a way that meets organisational and policy needs rather than respond to the realities of practice (Ayre and Preston-Shoot, 2010). This might explain, at least in part, why only one third of the frequency for the category of providing evidence is accompanied with an interpretation by professionals when discussing risk. Similarly, the categories of unpacking concepts, alternative explanations and recognising contradictions are forms of critical thinking that are less likely to align with prescriptive guidance. Such forms of thinking lie out with the prescribed guidance and are not only deemed unnecessary, they expose professionals to a greater chance of being blamed in the event of something going wrong. This limited use of critical thinking might reflect Roets et al's (2017) view of a 'paralysis' in professionals' thinking about children at risk. 


\section{Limitations of study}

Whilst the framework of critical thinking in this study is useful in terms of its practical application, it is not possible to know if the demonstration of one or more categories of critical thinking is more useful to children's outcomes. The concept of risk is also complex and the way it is applied to children who present a serious threat to others might not be the same for other children or different service user groups. The dominance of psychologists and social workers in the meetings provide a limited range of perspectives and a more balanced representation of professionals, including issues of gender and ethnicity, will give a more accurate reflection of practice. A strength of this study is that it engaged with the messy world of practice, however, it was not possible to examine the extent to which critical thinking might be shaped by other key concepts such as reflexivity, or aspects that include the professionals' expertise, personality, education, experience, caseload, quality of child-worker relationship and resources. Future research should consider such aspects along with different frameworks of critical thinking in order to give a more nuanced insight into the way professionals conceptualise risk within practice.

\section{Implications for practice and policy}

Critical thinking is dependent on a range of individual and situational factors (Taylor and White, 2001) and current social work policy should be creating opportunities that maximise such an important cognitive process in professional practice. The importance attributed to the relational elements of interpreting and using knowledge is highlighted in this study and by others (e.g. Horwath, 2007; Helm and Roesch-Marsh, 2017). A strategy for enhancing critical thinking is to maximise opportunities and support for social workers and related professionals to ask relevant questions and challenge each other when discussing risk. The categories of critical thinking about risk are often generated from the interaction between professionals in a way that involves two key elements:

1. the use of questions to prompt or challenge other professionals when seeking clarification and/or additional information;

2. the contributions from other professionals provide opportunities for additional knowledge, different perspectives and alternative interpretations.

These elements contribute to an iterative process that allows for categories of critical thinking to be prompted, questioned, challenged and developed. The use of questioning and contributions from professionals is present in all of the meetings in this study, albeit to different degrees, and their function in enhancing critical thinking reflects Eraut's (1994) emphasis on the 'deliberative analytical' mode of cognition required for practice. The critical thinking that emerges from these interactions allow social workers and other professionals to make more deliberative and analytical contributions to the discussion. Together, these are more likely to enable informed decision-making, better interpretation of evidence and a greater ability to theorise about risk, whilst simultaneously limiting errors of judgment due to insufficient evidence or inadequate explanations. This process of enhancing critical thinking through the interactions and contributions from others should be a priority when working with all vulnerable children. However, achieving this in relation to children who pose a risk 
of harm to others and in organisations that are structured on hierarchies of power and where status and knowledge vary within and across professional groups is less than straightforward. The barriers and constraints from procedures and guidance in social work can constrain practitioner thinking and discussion, and so the need to create safe spaces in which professionals can explore risk openly, and develop their skills in thinking about risk is essential.

\section{References}

Allardyce, S. and Yates, P.M. (2013) 'Assessing risk of victim crossover with children and young people who display harmful sexual behaviours', Child Abuse Review, 22, pp. 255-267.

Ayre, P. and Preston-Shoot, M. (eds) (2010) Children's Services at the Crossroads: A Critical Evaluation of Contemporary Policy for Practice, Lyme Regis, Russell HousePublishing.

Baker, K. (2008) 'Risk, uncertainty an public protection: Assessment of young people who offend', British Journal of Social Work, 38, pp. 1463-1480.

Barnett, R. (1997) Higher Education: A critical Business, Buckingham, Open University Press and Society for Research into Higher Education.

Barter, C. (2013) 'Children and young people who harm others', Child Abuse Review, 22, pp. 227-231.

Benbenishty R., Osmo, R. and Gold, N. (2003) 'Rationales provided for risk assessments and for recommended interventions in child protection: A comparison between Canadian and Israeli professionals', British Journal of Social Work, 33 (2), pp. 137-55.

Brown, K. and Rutter, L. (2008) Critical Thinking for Social Work, London, Macmillan.

Crawford, N.C. (2004) Understanding Discourse: A methods of ethical argument analysis, Qualitative \& Multi-Method Research, 2, pp. 22-25, doi.org/10.5281/zenodo.998663, downloaded https://zenodo.org/record/998633\#.W4fF4Wy0Wvo (last accessed 12/12/2019).

Crawford, R. (2004) 'Risk ritual and the management of control and anxiety in medical culture', Health, 8 (4), pp. 505-28.

Daniel, B., Wassell, S. and Gilligan, R. (2010) Child development for child care and protection workers, London, Jessica Kingsley.

D'Cruz, H. and Gillingham, P. (2017) 'Participatory research ideals and practice experience: Reflections and analysis', Journal of Social Work, 17 (4), pp. 434-452.

Deal, K. H. and Pittman, J. (2009) 'Examining predictors of social work students' critical thinking skills', Advances in Social Work, 10 (1), pp. 87-102.

Eraut, M. (1994) Developing Professional Knowledge and Competence, London, Falmer. 
Fusch, P. I. and Ness, L. R. (2015) 'Are we there yet? Data saturation in qualitative research', The qualitative report, 20 (9), pp. 1408-1416.

Gambrill, E. (2012) Critical Thinking in Clinical Practice, 3rd edn, Hoboken, NJ, Wiley.

Gray, M. and Schubert, L. (2013) 'Knowing what we know about knowledge in social work: The search for a comprehensive model of knowledge production', International Journal of Social Welfare, 22 (4), pp. 334-46.

Hackett, S., Masson, H., Balfe, M. and Phillips J. (2013) 'Individual, Family and Abuse Characteristics of 700 British Child and Adolescent Sexual Abusers', Child Abuse Review, 22, pp. 232-245.

Hardy, C., Harley, B. and Pillips, N. (2004) Discourse Analysis and Content Analysis: Two Solitudes?, Qualitative \& Multi-Method Research, 2, pp. 19-22,

doi.org/10.5281/zenodo.998649, downloaded

https://zenodo.org/record/998649\#.W4fC32y0Wvo (last accessed 12/12/2019).

Hardy, M. (2017) 'In Defence of Actuarialism: Interrogating the Logic of Risk in Social Work Practice', Journal of Social Work Practice, 31 (4), pp. 395-410.

Helm, D. (2011) 'Judgement or assumptions? The role of analysis in assessing children and young people's needs', British Journal of Social Work, 41 (5), pp. 894-911.

Helm, D. and Roesch-Marsh, A. (2017) 'The Ecology of Judgement: A Model for Understanding and Improving Social Work Judgements', The British Journal of Social Work, 47 (5), pp.1361-1376.

Horwath, J. (2007) 'The Missing Assessment Domain: Personal, Professional and Organizational Factors Influencing Professional Judgements when Identifying and Referring Child Neglect', British Journal of Social Work, 37 (8), pp.1285-1303.

Kuhn, D. (1991) The Skills of Argument, Cambridge, Cambridge University Press.

Laming, W. (2009) The Protection of Children in England: A Progress Report, London, The Stationery Office.

Maclellan, E. and Soden, R. (2001) Making explicit tutors' judgements about quality in students' academic writing in the Faculty of Education, Report of an initiative for the Teaching and Learning Quality Improvement Committee, Glasgow, University of Strathclyde.

Mayer, C., Lohmann, I. and Grosvenor, I. (2009) Children and youth at risk: Historical and international perspectives, Frankfurt am Main, Peter Lang. 
Munro, E. (2011) The Munro Review of Child Protection. Final Report. A Child Centred System, London, The Stationery Office.

Potter, J. (1996) Representing Reality: Discourse, Rhetoric and Social Construction, London, Sage.

Roets, G., Roose, R. and De Wilde, L. (2017) 'Framing the 'child at risk' in social work reports: Truth-telling or storytelling', Journal of Social Work, 17 (4), pp, 453-469.

Sheppard, M., Charles, M., Rees, P., Wheeler, M. and Williams, R. 'Inter-Personal and Critical-Thinking Capabilities in Those about to Enter Qualified Social Work: A Six-Centre Study', The British Journal of Social Work Advance Access, published May 31, 2018, doi.org/10.1093/bjsw/bcx143

Taylor, C. and White, S. (2001) 'Knowledge, truth and reflexivity: The problem of judgement in social work', Journal of Social Work, 1 (1), pp. 37-59.

Turney, D. and Ruch, G. (2016) 'Thinking about Thinking after Munro: The Contribution of Cognitive Interviewing to Child-Care Social Work Supervision and Decision-Making Practices', The British Journal of Social Work, 46 (1), pp. 669-685.

Whittaker, A. and Havard, T. (2016) 'Defensive practice as 'fear-based' practice: Social work's open secret?', British Journal of Social Work, 46 (5), pp. 1158-1174.

Figure Legend

Table 1 frequency of critical thinking for potential harm and actual harm in relation to the children or other people.

Figure 1- frequency of critical thinking about risk to the children and other people. 